\title{
A IMPORTÂNCIA DOS JOGOS COOPERATIVOS NO AMBIENTE ESCOLAR
}

\author{
THE IMPORTANCE OF COOPERATIVE GAMES IN THE SCHOOL ENVIRONMENT
}

\author{
Paulo Roberto Barbosa dos Santos ${ }^{1}$, Alexsandro Santos da Silva² \\ ${ }^{1}$ Faculdade Pitágoras, Teixeira de Freitas, BA, E-mail: basqueteescolinha2015@gmail.com, ORCID: \\ https://orcid.org/0000-0002-1645-0693
}

\begin{abstract}
${ }^{2}$ Faculdade Mantenense dos Vales Gerais- INTERVALE, Programa de Pós Graduação Psicopedagogia Clínica e Institucional, Brasil, E-mail: lex-1alex@hotmail.com, ORCID: https://orcid.org/0000-0001$\underline{8582-8381}$
\end{abstract}

\author{
ARTICLE INFO \\ Article history: \\ Received 2020-08-22 \\ Accepted 2020-09-04 \\ Available online 2020-11-30
}

Palavras-chave: Jogos cooperativos. Ambiente escolar. Educação física.

Keywords: Cooperative games. School environment. Physical education

RESUMO. Diante as tantas problemáticas como intolerância, falta de respeito, atos violentos, problemas psíquicos existentes dentro da Unidade Escolar, foi desenvolvido este trabalho com o objetivo de compreender o processo participativo dos alunos do Ensino Fundamental II, da Escola Municipal Alda Nunes Santos, buscando introduzir e demonstrar a importância dos jogos cooperativos no contexto escolar. Teve como metodologia a inserção de jogos cooperativos nos planejamentos das aulas de Educação Física, buscando acompanhar a participação dos alunos nesta mudança de métodos das aulas, aulas com jogos competitivos para cooperativos. Dos jogos existentes na Unidade Escolar, foram levantados muitos jogos com centralidade competitiva, a saber: Jogos como corrida de revezamento, pega-pega de corrente, vôlei e futsal e coelho sai da toca, o foco do estudo consistiu em adaptar as atividades, buscando inserir abordagens cooperativas. Durante o ano letivo foi perceptível a mudança dos alunos, a interação dos mesmos com os demais colegas. Mesmo sendo uma ótima alternativa para dos Professores de Educação Física, o uso desses jogos, é necessário ser cauteloso e ter uma diversificação desses jogos nos planejamentos para que não sejam desconfortáveis e monótonos o seu uso, pois assim os alunos poderão ter estímulo, tendo como resultado a participação de todos.

ABSTRACT. In the face of so many problems such as intolerance, lack of respect, violent acts, psychological problems existing within the School Unit, this work was developed with the objective of understanding the participatory process of students of Elementary School II, from the Municipal School Alda Nunes Santos, seeking to introduce and demonstrate the importance of cooperative games in the school context. It had as methodology the insertion of cooperative games in the planning of Physical Education classes, seeking to accompany the participation of students in this change of methods of classes, classes with competitive games for cooperatives. Of the games that existed in the School Unit, many games with competitive centrality were raised, namely: Games such as relay race, chain catch, volleyball and futsal and rabbit comes out of the hole, the focus of the study was to adapt activities, seeking to insert cooperative approaches. During the school year the students' change was noticeable, their interaction with other colleagues. Even though it is a great alternative for Physical Education Teachers, the use of these games, it is necessary to be cautious and have a diversification of these games in the planning so that their use is not uncomfortable and monotonous, so that students can have stimulus, having as result the participation of all. 


\section{Introdução}

A realidade da disciplina Educação Física no ambiente escolar está diretamente ligada às práticas demasiadamente competitivas, sendo que de acordo com Maia (2007), estas práticas têm como vantagem a participação de um treinamento para o mundo competitivo que temos. No entanto, o aluno que só participa de aulas que tendem a competição, só aprende a ter como objetivo: vencer (SILVA, 2013). Isso é um fator que dificulta o relacionamento das pessoas, gerando um clima de rivalidade e estresse (BARRETO, 2007).

Além disso, o avanço tecnológico, a globalização e a sociedade cada vez mais com um ego preeminente competitiva e individualista, são motivos que contribuem para esta dificuldade no relacionamento das pessoas, pois gera a intolerância e a falta de respeito entre elas (MACHADO \& STINGHEN, 2016).

Culturalmente, o jogo desempenha papel importante nas interações sociais, potencializa o respeito à afetividade na sua relação com o meio social, além de diversas formas de vivência, desenvolvimento cultural, domínio motor e cognitivo das pessoas (FONSECA \& SILVA, 2013).

Para Huizinga (2000):

O jogo é uma atividade ou ocupação voluntária, exercida dentro de certos e determinados limites de tempo e de espaço, segundo regras livremente consentidas, mas absolutamente obrigatórias, dotado de um fim em si mesmo, acompanhado de um sentimento de tensão e de alegria e de uma consciência de ser diferente da "vida cotidiana". (HUIZINGA, 2007, p. 33)

Jogos como corrida de revezamento, pega-pega de corrente, vôlei e futsal misto (menina e menino), coelho sai da toca, são algumas atividades que podem ter cunho cooperativo e competitivo. Cooperação e competição são processos distintos, porém para Brotto, (1999) pode-se aproximá-los de modo a tornar a competição cooperativa e a cooperação competitiva.

De acordo com Vandelão (2004) para trabalhar a totalidade do aluno, é necessário que tenha acesso a experiências competitivas e cooperativas, vivenciando assim as duas formas de jogos.

Na educação física escolar, o professor pode utilizar-se de várias formas culturais para desenvolver nos seus alunos papeis como relatados anteriormente, como o uso de jogos cooperativos. Segundo Deacove (2002), estes jogos têm estrutura alternativa onde os envolvidos não jogam contra, mas sim com os outros.

Ao optarmos pela temática cooperação, não estamos excluindo a importância da competição, tendo em vista a necessidade para evitar frustrações existentes na vivência social. A problemática aqui expressa é a centralidade existente nas aulas de Educação Física em atividades competitivas. 
Este estudo tem por objetivo compreender o processo participativo dos alunos do Ensino Fundamental II, da Escola Municipal Alda Nunes Santos, buscando introduzir e demonstrar a importância dos jogos cooperativos no contexto escolar.

\subsection{A importância dos Jogos cooperativos}

Os jogos cooperativos surgiram há milhares de anos, através de comunidades tribais que se reuniam para celebrar a vida (ORLICK, 1978). Brotto (1997) afirma que, os jogos cooperativos surgiram a partir de preocupação com a excessiva valorização dada ao ego, ao individualismo e a competição exacerbada.

Por contribuir na formação integral dos alunos, os jogos cooperativos foram criados com o foco de promover, nos envolvidos, a autoestima, além de incentivar uma melhor convivência social, pois todos estão com o mesmo objetivo, assim valoriza o trabalho em equipe (MENDES et al; 2009). Têm como objetivo favorecer o aprendizado por meio da cooperação entre os envolvidos, favorecer a aproximação entre as pessoas, sem a existência da competição (FONSECA \& SILVA, 2013).

Segundo Silva et al (2012) o trabalho em equipe é mais produtivo, além de ter o seu caráter vantajoso e eficiente ao se comparar com o trabalho individualizado. Soler (2011) afirma que os jogos cooperativos apresentam características libertadoras, libertam da competição, da eliminação, libertam para criar, além de libertar de agressões físicas, pois diminui as pressões existentes em competições.

É comum, sejam em escolas públicas ou privadas, comportamento agressivo de alunos que se dá por meio de insultos, além de ameaças, acusações injustas, levando na maioria das vezes o agredido a problemas psíquicas e à exclusão escolar e social (ROSA, 2010), portanto, tendo em vista as características libertadoras, os jogos cooperativos tornamse relevantes para a mudança desse cenário.

Nas aulas de Educação Física há uma predominância de um espírito competitivo através dos jogos que buscam um vencedor, portanto é de suma importância o rompimento disso (CORREIA, 2007), buscando compreender a verdadeira vitória.

O professor de Educação Física tem o compromisso em disseminar os valores positivos para que os seus alunos possam compreender que a verdadeira vitória não depende da derrota do outro, mas sim, compreender que todos possuem habilidades e potenciais, todos têm importantes papeis na realização das tarefas conjuntas (VIEIRA, 2013).

De acordo com Almeida (2003) a ideia básica da proposta pelo jogo cooperativo é de permitir uma mudança no indivíduo, mudança de sentimentos, potencializar as Habilidades Humanas Básicas como, por exemplo, o amor, a alegria, a confiança, o respeito, a autonomia, entre tantas outras habilidades. 
Por fim, os jogos cooperativos podem possibilitar vários resultados positivos no ambiente escolar, com a melhoria da relação existente entre os alunos, pois jogar sem competir há uma necessidade de colaboração, união entre os envolvidos (ANTUNES, 2016).

\subsection{Jogos cooperativos VS Jogos competitivos}

Antigamente, o jogo era visto como um passatempo, atualmente, todas as áreas do conhecimento fazem uso do jogo, além de defenderem a sua inclusão, pois, além do seu poder educativo, proporciona momentos de alegria, prazer, fantasia e descontração (SOLER, 2008).

Enquanto os jogos competitivos tem um vencedor em detrimento a perdedor, nos jogos cooperativos todos são vencedores. Brotto (2001) citado por Silva (2015) nos mostra algumas diferenças entre as duas modalidades de jogos.

\begin{tabular}{|l|l|}
\hline \multicolumn{1}{|c|}{ JOGOS COMPETITIVOS } & \multicolumn{1}{c|}{ JOGOS COOPERATIVOS } \\
\hline Divertido somente para alguns & Divertido para todos \\
\hline Derrota para alguns & Vitória para todos \\
\hline Aprendizados: desconfiança e egoísmo & Aprendizados: confiança e cooperação \\
\hline $\begin{array}{l}\text { Os perdedores somente observam e } \\
\text { não desenvolvem habilidades }\end{array}$ & $\begin{array}{l}\text { Desenvolvimento das capacidades e } \\
\text { habilidades por mais tempo }\end{array}$ \\
\hline Jogador se torna mais independente & Jogador se torna mais solidário \\
\hline Somente alguns serão bem sucedidos & $\begin{array}{l}\text { Todos aprendem a crescer e } \\
\text { desenvolver melhor }\end{array}$ \\
\hline
\end{tabular}

Figura 1 Diferença entre jogos competitivos e cooperativos.

Fonte: BROTTO, 2001; SILVA, 2015

Como podemos verificar na tabela comparativa entre as duas modalidades, os jogos cooperativos em relação as questões socioafetivas são bem mais vistas, pois todos os integrantes estão em prol de um objetivo comum, todos vencem.

\subsubsection{Tipos de jogos e abordagens}

\section{Pega corrente}

Semelhante ao pega-pega tradicional, porém aqui cada jogador que for capturado se une formando uma corrente, é um jogo integralmente cooperativo. Para isso, os alunos devem criar estratégias para pegar todos os integrantes, mas, de acordo com Soler (2002) só vale pegar o colega se todos da corrente estão unidos, de mãos dadas. 


\section{Futsal misto e vôlei misto}

Consiste no jogo do tradicional futebol e vôlei, porém a diferença está na formação de dois times, sendo que ambos terão meninos e meninas jogando, é uma atividade de cunho competitivo, mas o foco aqui é a cooperação existente entre os meninos com as meninas, quebrando os estereótipos existentes na sociedade. Sendo ponto de partida para o combate da desigual (AUAD, 2006).

\section{Corrida de revezamento misto}

Para a realização desta atividade, disponha os alunos em fila (uma para cada equipe), tendo cada equipe alunos de ambos os sexos, dê um bastão para o primeiro de cada fila. $O$ objetivo é correr, dar a volta em cones que se encontra a um certo distanciamento dos alunos e passar o bastão para o próximo da fila até que todos da equipe venha a completar a corrida. A corrida de revezamento misto necessita de cooperação entre os envolvidos de cada equipe para que possa "vencer" a competição, ou seja, possui cunho cooperativo e competitivo.

Toca coelho (bambolê)

Os alunos devem sair da toca (bambolê) e procurar por outra. Quem estiver sem toca buscará o lugar de outro. O aluno que ficar de fora será o 'coelhinho perdido'. Por mais que aparentemente é integralmente competitivo, a diferença aqui é inserir abordagem cooperativa, desta forma, os alunos formam duas equipes (duas famílias) e cada integrante de sua respectiva família tende a se esforçar para conseguir a "toca" para sua família, "vence" que cooperou mais para ajudar os integrantes da própria equipe, pois toda a equipe tem como resultado final a sua moradia.

\section{Desenvolvimento}

O presente trabalho foi realizado na Unidade Escolar denominada Escola Municipal Alda Nunes Santos, localizada no extremo sul da Bahia, no município de Caravelas, entre as coordenadas 17043'55" S; 39³3'03" W (SILVA, 2016 apud SILVA, 2019), escola em que um dos autores atua como professor de Educação Física.

Para este estudo usou uma abordagem qualitativa, pesquisa exploratória e bibliográfica. Tendo como estratégia metodológica, a oferta de atividades de caráter cooperativo, seguindo o método usado por Vieira (2012) em observação nas aulas de Educação Física e as referidas mudanças nas relações dos alunos.

Antes de iniciar qualquer atividade com os alunos, buscou analisar o planejamento anual da disciplina Educação Física, verificando quais jogos estavam inclusos no planejamento.

Foi introduzido na escola citada os jogos cooperativos, envolvendo as turmas do $6^{\circ}$ ao 9 ano do Ensino Fundamental, foram apresentadas na disciplina Educação Física, aulas teóricas e práticas sobre jogos e brincadeiras, destacando a mudança de práticas competitivas para cooperativas. 
As aulas tinham a mesma abordagem: iniciava com uma roda de conversa, falava sobre os objetivos da dinâmica do dia, iniciava as atividades e terminava da mesma forma que começou, ou seja, com uma roda de conversa.

\title{
3. Resultados e Discussão
}

Os jogos cooperativos podem ser praticados, inseridos no planejamento da escola, aqui se tratando das aulas de Educação Física, como uma estratégia socioeducativa, porém para isso, é necessário a introdução desta estratégia pouco a pouco de forma que a criança não tenha um choque com o método de cooperação tendo em vista o seu pensamento individualista e egocêntrico trazido de fora do ambiente escolar (MAIA; MAIA; MARQUES, 2007), pensando nisso, a estratégia adotada nas aulas de Educação Física foi inserir os jogos cooperativos, porém buscando também aquelas atividades que eram mistas, parte de cada modalidade.

De acordo com Orlick (1989) jogos cooperativos podem ser caracterizados da seguinte forma:

\begin{abstract}
Jogo cooperativo sem perdedores: São os jogos plenamente cooperativos, pois todos jogam juntos para superar um desafio comum e não há perdedores. Jogos cooperativos de resultado coletivo: São formadas duas ou mais equipes, mas o objetivo do jogo só é alcançado com todos jogando juntos, por um objetivo ou resultado comum a todos. Jogo de inversão: Esses quebram o padrão de times fixos, em que dependendo do jogo, os jogadores trocam de times a todo instante, dificultando reconhecer vencedores e perdedores. Jogos semicooperativos: Esses jogos favorecem o aumento da cooperação do grupo, e oferece as mesmas oportunidades de jogar para todas as pessoas do time, mesmo um com menor habilidade, pois existem regras para facilitar a participação desses. Os times continuam jogando um contra o outro, mas a importância do resultado é diminuída, pois a ênfase passa ser o envolvimento ativo no jogo e a diversão.
\end{abstract}

Como é destacado acima, não é visível de forma clara um perdedor, tendo em vista a centralidade da modalidade cooperativa. Conforme Silva (2017) através desta modalidade o aluno tende a jogar pelo prazer de participar do jogo, não busca garantir uma premiação, que muitas vezes são conseguidos somente por uma minoria.

A criança que desenvolve-se em um ambiente que atos violentos são explícitos em seu cotidiano, é induzido inconscientemente a esse tipo de conduta, pois a criança se espelha no modo de vida presente na sua comunidade, e com isso acaba levando atitudes violentas para suas brincadeiras, assim a prática de jogos violentos, abusivos, atos agressivos, faz com que a criança tenha atos semelhantes em suas relações com as pessoas (MORAIS; MOLINA, 2008), fato que pode explicar a relação violenta de uma aluno com os demais colegas. 
O jogo possui caráter social, podendo ser transmitido de para pessoa, podendo ser transformado em tradição. Mesmo depois de o jogo ter finalizado, ele permanece como uma criação nova do espírito, um tesouro a ser conservado pela memória (HUIZINGA, 2007).

Tendo um caráter de solidariedade e não de exclusão (BROTTO, 2001), os alunos devem ser estimulados através de desafios, com a participação de todos os envolvidos, tendo como resultado a satisfação da coletividade, resultado obtido com muitas atividades desenvolvidas no ano letivo com os alunos da Escola Municipal Alda Nunes Santos (Fig. 2).
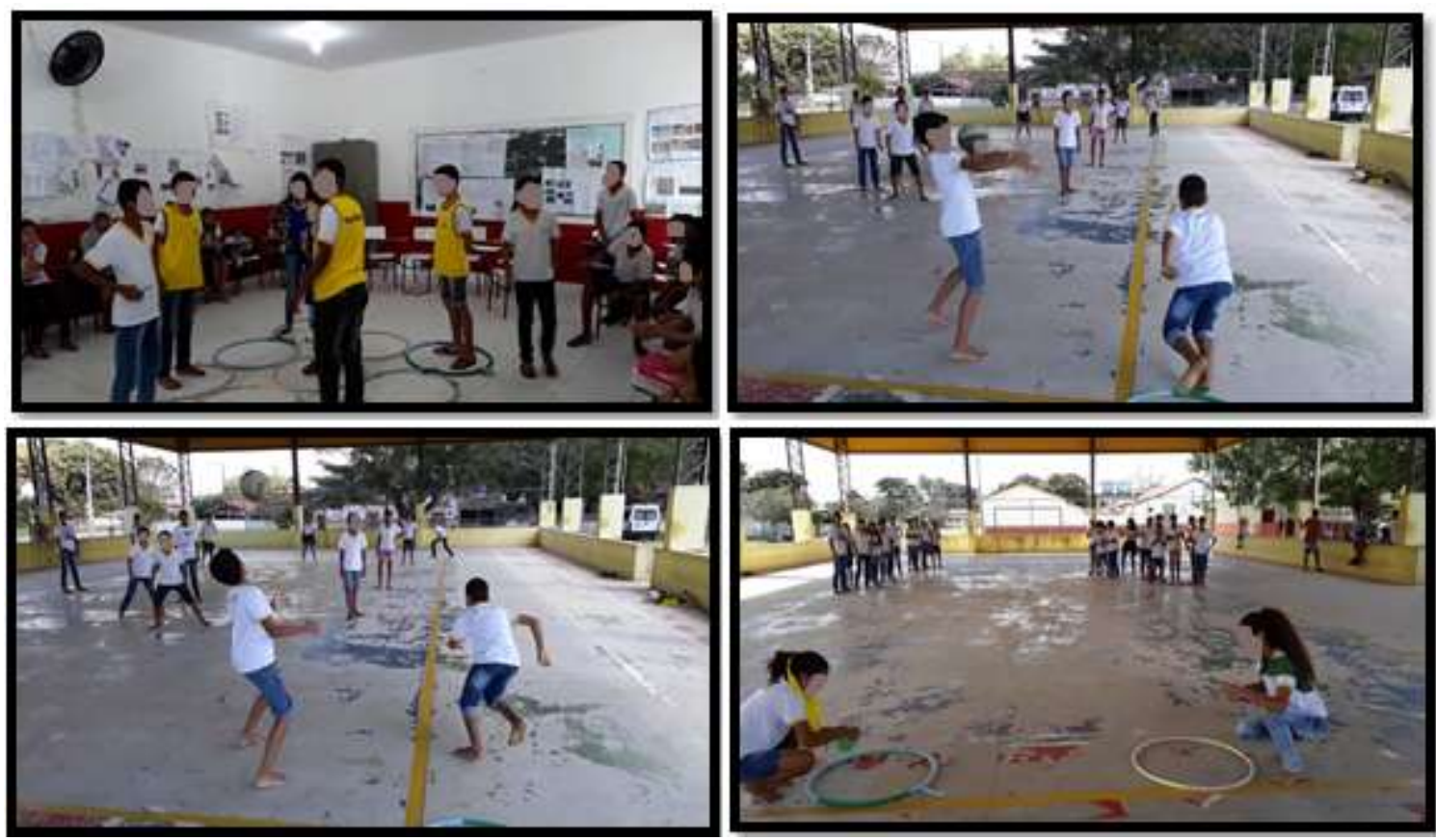

Figura 2 - Jogos cooperativas realizados pelos alunos da Escola Municipal Alda Nunes Santos.

Fonte: Arquivo pessoal

A redução de intrigas, brigas, preconceito, e o aumento do respeito foram perceptíveis durante o ano letivo, reduzindo assim meios repreensivos como punição, castigo aos alunos na unidade Escolar. Resultado semelhante encontrado por Schwartz; Bruna; Luba (2003) ao trabalhar com uma escola da rede pública da cidade de Rio Claro, São Paulo, Brasil.

Sabendo o valor positivo na aprendizagem dos alunos, novos trabalhos com Jogos Cooperativos vêm surgindo, sendo possível muitas formas para abordar isso no contexto escolar (MORAIS; MOLINA, 2007), ciente disso foi possível desenvolver um ótimo trabalho com os alunos, diversificando as aulas de Educação Física com diferentes jogos desta modalidade.

Dentre as atividades realizadas pelos os alunos, temos os jogos como corrida de revezamento, coelho sai da toca, vôlei e futsal misto (menina e menino) (fig. 3) e a atividade pega-pega de corrente (fig.4), os dois últimos listados chamaram a atenção e interesse dos alunos, relevante a serem discutidos neste trabalho. Cabe ressaltar que ao analisar o planejamento anual da disciplina Educação Física, estes jogos já existiam, porém a 
centralidade era a competitividade, devido a isto, a proposta foi a adaptar as atividades, buscando inserir abordagens cooperativas.
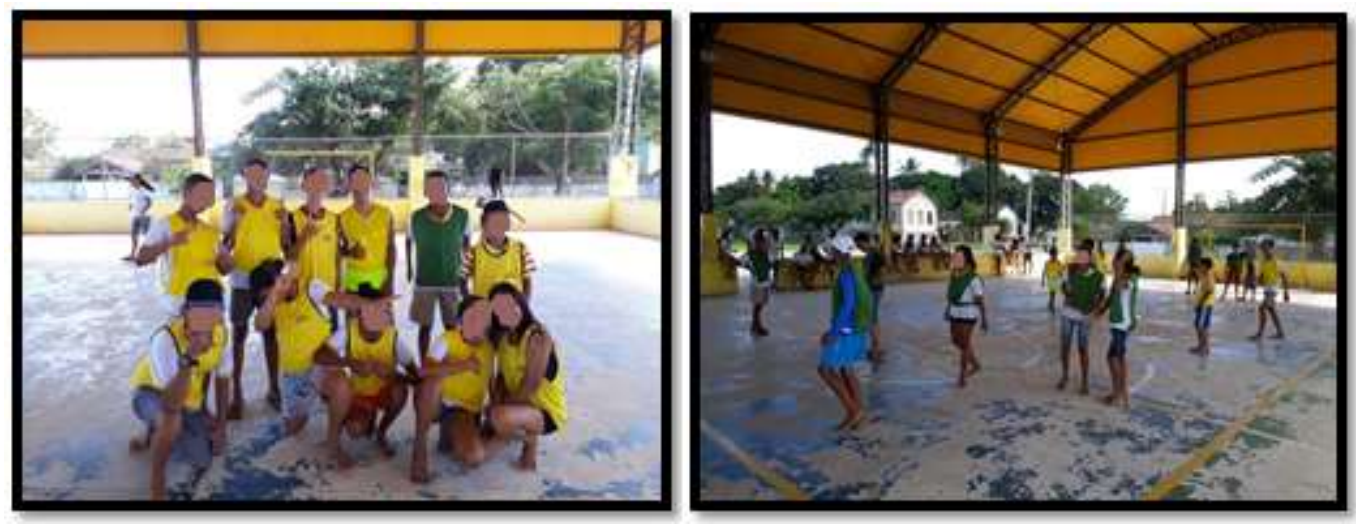

Figura 3 - Futsal Misto praticada pelos alunos da Escola Municipal Alda Nunes Santos. Fonte: Arquivo pessoal

Tendo em vista os paradigmas existentes na sociedade atual, onde a prática desportiva e a divisão de tarefas têm como critério o gênero. A aula de Educação Física, por sua vez, acaba fortalecendo estes paradigmas (LIMA \& DINIS, p.6, 2007), criando assim uma discriminação entre os gêneros.

Quebrando os paradigmas existentes na sociedade atual, o Futsal misto consiste em partida de futsal que integra meninos e meninas no mesmo grupo, o time só pode jogar contra outro time misto, algo bem aceito e respeitoso por alunos de ambos os gêneros.

O pega-pega corrente consiste em inicialmente uma criança correndo atrás das outras. Quando alguém é pego, dá a mão para o pegador e passa a atuar em dupla com ele. Em seguida, vai atrás de outra criança, aumentando assim a corrente.
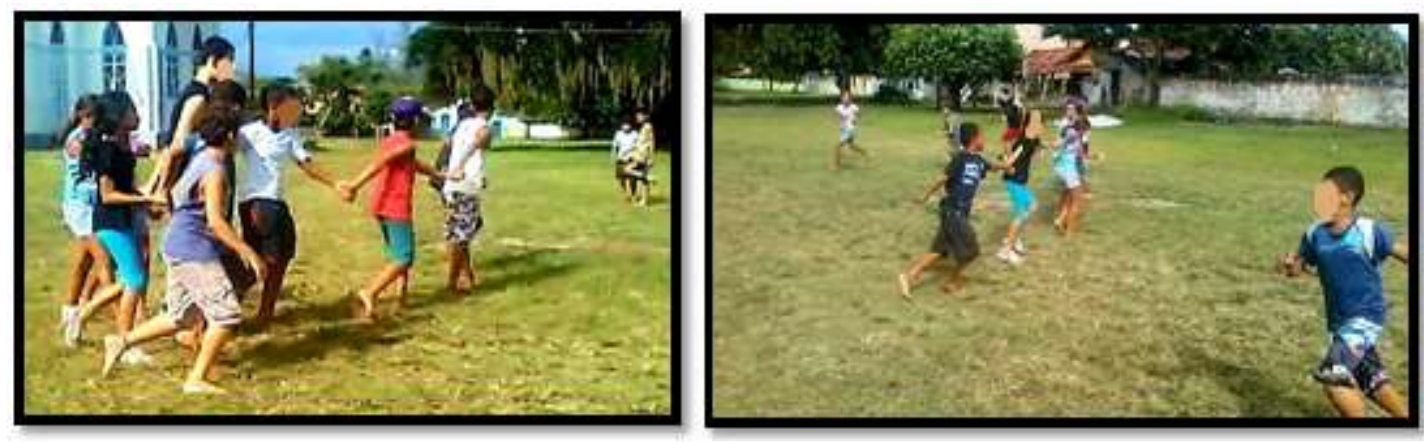

Figura 4- Pega-pega corrente com os alunos da Escola Alda Nunes Santos

Fonte: Arquivo pessoal

Segundo Amaral, (2009) os jogos cooperativos são atividades desenvolvidas em grupos, exigindo esforço e colaboração de cada um, todos indo pelo mesmo caminho para 
conseguirem juntos atingir um mesmo objetivo. Argumento este, que corrobora com o resultado da dinâmica pega-pega corrente.

Diante do envolvimento dos alunos com as propostas das aulas de Educação Física, ficou evidente o grau de concordância, aprendizados de grandes valores éticos, morais, sociais e afetivos, além da colaboração dos alunos com o jogo, professor e com os colegas, refletindo em um resultado positivo. Resultado semelhante encontrado por Comparin (2012) em seu trabalho de conclusão de curso intitulado "Jogos Cooperativos como Fator de Motivação e Socialização".

Por fim, dentro desta modalidade, o professor de Educação Física deve elaborar com cuidado o seu plano de aula, pois a sua função é ir além de cumprir uma carga horária, o profissional busca mudança de atitudes, para isso, conforme foi dito, é necessário diversificação do planejamento, caso contrário, as aulas não farão efeito no indivíduo, serão monótonas e sem graça para os alunos.

\section{Considerações finais}

Através deste trabalho foi possível compreender a importância da inclusão dos Jogos Cooperativos no Ambiente Escolar, tendo em vista muitos comportamentos inadequados que refletem em violência, falta de respeito, individualismo e tantos outros comportamentos dos alunos dentro e fora da escola.

Os jogos cooperativos oportunizam a mudança interpessoal, mudança de ato de vivência dos alunos que estão acostumados a serem competitivos, pois busca a valorizar a participação de todos, sendo assim é uma oportunidade para serem mais afetivos e respeitosos para com todos os envolvidos.

Cabe ressaltar que mesmo sendo uma ótima alternativa para os Professores de Educação Física, o uso desses jogos, é necessário ser cauteloso quanto a sua introdução dentro dos planejamentos de aula, para que não venha causar no aluno um desconforto, sabendo a existência de alunos que possuem espírito competitivo e individualista. Recomenda-se ainda, a diversificação desses jogos nos planejamentos para que não sejam monótonos, pois assim os alunos poderão ter estímulo, tendo como resultado a participação, aceitação e satisfação de todos.

\section{Referências}

ALMEIDA, Marcos. Jogos Cooperativos na Educação Física: uma proposta lúdica para a paz. III Congresso Estatal y I Iberoamericano de Actividades Físicas Cooperativas. Gijón (Astúrias). Ceará, 2003.

AMARAL, Jader Denicol do. Jogos Cooperativos. 4 ed. São Paulo: Phorte, 2009. 
ANTUNES, Celso. O Jogo e a Educação Física Infantil: falar e dizer, olhar e ver, escutar e ouvir. Petrópolis (RJ): Editora Vozes, 2003.

AUAD, Daniela. Educar meninas e meninos: relações de gênero na escola. São Paulo: Contexto, 2006.

BARRETO, A. V. Jogos cooperativos e a cultura da cooperação. Jogos Cooperativos, 2002.

BROTTO, Fábio Otuzi. Jogos Cooperativos: Para jogar uns com os outros e venSer... Juntos. Santos (SP): Projeto Cooperação, 1997.

BROTTO, F. Jogos Cooperativos: o jogo e o esporte como um exercício de convivência. Santos: Projeto Cooperação, 2001.

COMPARIN, Elaine. Jogos cooperativos como fator de motivação e socialização. 2012. 15 f. Trabalho de Conclusão de Curso (Graduação). Faculdade Pinhalzinho - Horus Faculdades, SC, 2012.

CORREIA, M. M. Jogos cooperativos e Educação Física escolar: possibilidades e desafios. In: EFDeportes.com, Revista digital. Buenos Aires, ano 12, n.107, abril de 2007.

DEACOVE, Jim. Manual de Jogos Cooperativos. Santos. Projeto Cooperação, 2002.

FONSECA, Fernando Richardi da; SILVA, E. A. P. C. Os jogos cooperativos na Educação Física escolar: favorecimento das relações interpessoais. ConScientiae Saúde (Online), v. 12, p. 588-597, 2013.

HUIZINGA, Johan. Homo ludens: o jogo como elemento da cultura. 5 edição. São Paulo: Perspectiva, 2007.

LIMA, Francis Madlener de; DINIS, Nilson Fernandes. Corpo e Gênero nas práticas escolares de educação física. Currículo sem fronteiras, v.7, n.1, pp.243-252, Jan/Jun 2007.

MAIA, Raquel Ferreira; MAIA, Jusselma Ferreira; MARQUES, Pinto. Jogos cooperativos x jogos competitivos: um desafio entre 0 ideal e 0 real. São Paulo: Faculdades Metropolitanas Unidas, 2007.

MACHADO. Andréa de Lara; STINGHEN. Fábio Mucio. A importância dos jogos cooperativos no ensino fundamental: convivendo em harmonia. In: PARANÁ. Secretaria de Estado da Educação. Superintendência de Educação. Os Desafios da Escola Pública Paranaense na Perspectiva do Professor PDE: Produção Didático-pedagógica, 2013. Curitiba: SEED/PR., 2016. V.1. (Cadernos PDE). ISBN 978-85-8015-076-6.

MENDES, L. C.; PAIANO, R.; FILGUEIRAS, I. P. Jogos cooperativos: eu aprendo, tu aprendes e nós Cooperamos. Revista Mackenzie de Educação física e Esporte. São Paulo. V. 8, n. 2, 2009.

MORAIS, Vera L.; MOLINA, Rosane Kreusburg. Jogos cooperativos e processos educativos. Revista de ciências humanas. Revista de Ciências Humanas, Capa > v. 9, n. 13, 2008.

ORLICK, T. Vencendo a competição. São Paulo: Círculo do Livro, 1989. 
ROSA, Maria José Araujo. A violência no ambiente escolar: diferenças e preconceitos refletindo no processo ensino aprendizagem. In: V Fórum Identidades e Alteridades - I Congresso Nacional Educacional e Diversidade, 2011, Itabaiana/Se. V Fórum Identidade e Alteridades. São Cristovão/Se: UFS, 2011. V. I. P. 1-31.

SILVA, Maria Gabriela Leão da. Jogos cooperativos e sua utilização no ensino fundamental. 2017, 25 f. Trabalho de conclusão de Curso (Graduação). Faculdade de Ciências da Educação e Saúde Centro Universitário de Brasília - UniCEUB, Brasília, 2015.

SILVA, Valdenir Lisboa da. Jogos cooperativos no ensino fundamental: uma proposta de interação social de alunos do 6ํㅜ $7^{\circ}$ Ano. In: PARANÁ. Secretaria de Estado da Educação. Superintendência de Educação. Os Desafios da Escola Pública Paranaense na Perspectiva do Professor PDE: Produção Didático-pedagógica, 2013. Curitiba: SEED/PR., 2016. V.1. (Cadernos PDE). ISBN 978-85-8015-076-6.

SILVA, Marlon Danilo Ribeiro da. A importância dos jogos cooperativos como fator de inclusão social nas séries iniciais do ensino fundamental. 2015, 20 f. Trabalho de conclusão de Curso (Graduação). Faculdade de Ciências da Educação e Saúde Centro Universitário de Brasília - UniČUB, Brasília, 2015.

SILVA, Alexsandro Santos da. Líquens como bioindicadores de poluição atmosférica na cidade de Caravelas - Ba, Brasil. Revista Científica Multidisciplinar Núcleo do Conhecimento. Ano 04, Ed. 07, Vol. 14, pp. 75-86. Julho de 2019. ISSN: 2448-0959

SILVA, J. K. F; DOHMS, F. C.; CRUZ, L. M.; TIMOSSI, L. S. Jogos Cooperativos: contribuição na escola como meio socializador entre crianças do Ensino Fundamental. Motrivivência, ano 24, n. 39, p. 195-205, 2012.

SOLER, R. Brincando e Aprendendo com os Jogos Cooperativos. Rio de Janeiro: $3^{\text {a }}$ edição: Sprint, 2011

SOLER, R. Brincando e aprendendo com os jogos cooperativos. Rio de Janeiro: Sprint; 2008

SCHWARTZ, G. M.; BRUNA, H. C; LUBA, G. M. Jogos Cooperativos no processo de interação social: visão de professores. In: Universidade Estadual Paulista. (Org.). Núcleos de Ensino, 2003, v. 1, p. 253-262.

VANDELÃO, E. P. L. A contribuição dos jogos cooperativos no desenvolvimento socioafetivo de crianças de 07 a 10 anos de idade: um relato de experiência. Monografia. Faculdade Dom Bosco. Curitiba. 2004, p. 38-39.

VIEIRA, Martha Bezerra. A importância dos jogos cooperativos como conteúdo de ensino nas aulas de Educação Física infantil. Lecturas Educación Física y Deportes (Buenos Aires), v. 01, p. 1-15, 2013.

VIEIRA, Márcia Gonçalves. Jogos cooperativos, sua importância e Aceitação nas aulas de educação física. 2012. 44 f. Trabalho de Conclusão de Curso (Especialização)Universidade de Brasília, Brasília, 2012. 